ISSN 1112-9867

Available online at $\quad$ http://www.jfas.info

\title{
PORTFOLIO OPTIMIZATION OF THE CONSTRUCTION SECTOR COMPANIES IN MALAYSIA WITH MEAN-SEMI ABSOLUTE DEVIATION MODEL
}

\author{
W. H. Lam ${ }^{1, *}$, S. H. Jaaman ${ }^{2}$ and W. S. Lam ${ }^{1}$ \\ ${ }^{1}$ Centre for Mathematical Sciences, Centre for Business and Management, Department of \\ Physical and Mathematical Science, Faculty of Science, Universiti Tunku Abdul Rahman, \\ 31900 Kampar, Perak, Malaysia \\ ${ }^{2}$ School of Mathematical Sciences, Faculty of Science and Technology, Universiti \\ Kebangsaan Malaysia, 43600 Bangi, Selangor, Malaysia
}

Published online: 17 October 2017

\begin{abstract}
Portfolio optimization is an important investment strategy to find the trade-off between the risk and return. In mean-semi absolute deviation model,semi absolute deviation is employed as risk measure while the expected return of the investors is represented by the mean return. The objective of this paper is to construct the optimal portfolio that will minimize the portfolio risk and can achieve the investors target rate of return by using the mean-semi absolute deviation model. The data of this study comprises 20 construction sector companies that listed in Malaysia stock market from July 2011 until June 2016. The results of this paper show that the constructed optimal portfolio can minimize the portfolio risk at the expected rate of return. In addition, the composition of the companies invested in the optimal portfolio is different.
\end{abstract}

Keywords: portfolio risk; return; investment; investors.

\footnotetext{
Author Correspondence, e-mail: whlam@utar.edu.my

doi: http://dx.doi.org/10.4314/jfas.v9i5s.2
} 


\section{INTRODUCTION}

Risk and return are two important parameters to be considered in the investment. Investors wish to minimize the risk of loss and achieve the target rate of return in their investment. Portfolio optimization is an important strategy in investment to construct the optimal portfolio that will minimize the portfolio risk at the expected rate of return. Konno and Yamazaki [1] have proposed the mean-absolute deviation model in portfolio optimization to minimize the portfolio risk and can get the expected rate of return. The absolute deviation is used as risk measure in the mean-absolute deviation model. On the other hand, the expected return of the investors is represented by the mean return. The mean-absolute deviation model has been studied by the past researchers in portfolio optimization [2-5]. Speranza [6] has further introduced the mean-semi absolute deviation model. The semi absolute deviation model is employed to measure the portfolio risk. The mean-semi absolute deviation model has been studied in the past [7-9]. The mean-semi absolute deviation model is an optimization model with its objective function to minimize the portfolio risk which is semi absolute deviation. The optimization models have also been applied in different areas other than portfolio such as supply chain [10], production [11], harvesting [12] and palm oil [13]. The researches on portfolio optimization have not been actively studied in Malaysia using the mean-semi absolute deviation model. The objective of this study is to construct the optimal portfolio that will minimize the portfolio risk and can achieve the investors target rate of return by using the mean-semi absolute deviation model in the portfolio optimization of the construction sector companies that listed in Malaysia stock market. The rest of the paper is structured as follows. The next section describes the materials and methods. Section 3 discusses about the empirical results of this paper. Section 4 concludes the paper.

\section{MATERIAL AND METHOD}

\subsection{Material}

The data of this study consists of 20 construction sector companies that listed in Malaysia stock market. The period of this study covers from July 2011 until June 2016. Table 1 presents the name list of 20 construction sector companies in this study with abbreviation. 
Table 1. Name list of 20 construction sector companies

\begin{tabular}{|c|c|}
\hline Abbrevation & Name of Companies \\
\hline ASUPREM & ASTRAL SUPREME BERHAD \\
\hline AZRB & AHMAD ZAKI RESOURCES BERHAD \\
\hline BENALEC & BENALEC HOLDINGS BERHAD \\
\hline BPURI & BINA PURI HOLDINGS BHD \\
\hline CRESBLD & CREST BUILDER HOLDINGS BERHAD \\
\hline EKOVEST & EKOVEST BERHAD \\
\hline FAJAR & FAJARBARU BUILDER GROUP BHD \\
\hline GADANG & GADANG HOLDINGS BHD \\
\hline GAMUDA & GAMUDA BERHAD \\
\hline HSL & HOCK SENG LEE BERHAD \\
\hline IJM & IJM CORPORATION BERHAD \\
\hline JAKS & JAKS RESOURCES BERHAD \\
\hline KEURO & KUMPULAN EUROPLUS BERHAD \\
\hline KIMLUN & KIMLUN CORPORATION BERHAD \\
\hline MITRA & MITRAJAYA HOLDINGS BERHAD \\
\hline MUDAJYA & MUDAJAYA GROUP BERHAD \\
\hline MUHIBAH & MUHIBBAH ENGINEERING (M) BHD \\
\hline PRTASCO & PROTASCO BERHAD \\
\hline PUNCAK & PUNCAK NIAGA HOLDINGS BERHAD \\
\hline WCT & WCT HOLDINGS BERHAD \\
\hline
\end{tabular}

\subsection{Mean-Semi Absolute Deviation Model}

Konno and Yamazaki [1] have introduced the absolute deviation as the risk function, which is shown as follows:

$$
w(x)=E\left[\left|\sum_{j=1}^{n} R_{j} x_{j}-E\left[\sum_{j=1}^{n} R_{j} x_{j}\right]\right|\right]
$$

The mean-absolute deviation model [1] is formulated as follows:

$$
\text { Minimize } \quad w(x)=E\left[\left|\sum_{j=1}^{n} R_{j} x_{j}-E\left[\sum_{j=1}^{n} R_{j} x_{j}\right]\right|\right] \text { (2) }
$$


subject to

$$
\begin{gathered}
\sum_{j=1}^{n} E\left[R_{j}\right] x_{j} \geq \rho M_{0} \\
\sum_{j=1}^{n} x_{j}=M_{0}(4) \\
0 \leq x_{j} \leq u_{j, j}=1, \ldots, n
\end{gathered}
$$

where $R_{j}$ is the return of asset $j, x_{j}$ is the amount invested in asset $j, \rho$ is a parameter representing the minimal rate of return required by an investor, $M_{0,}$ is the total amount of fund and $u_{j}$ is the maximum amount of money which can be invested in asset $j$.

Konno and Yamazaki [1] assume $\mathrm{r}_{j t}$ be the realization of random variable $R_{j}$ during period $t$ $(t=1,2, \ldots, T)$, then

$$
\mathrm{r}_{j}=E\left[R_{j}\right]=\sum_{t=1}^{T} \frac{r_{j t}}{T}
$$

$w(x)$ can be approximated as follows:

$$
E\left[\left|\sum_{j=1}^{n} R_{j} x_{j}-E\left[\sum_{j=1}^{n} R_{j} x_{j}\right]\right|\right]=\frac{1}{T} \sum_{t=1}^{T}\left|\sum_{j=1}^{n}\left(r_{j t}-r_{j}\right) x_{j}\right|(7)
$$

where

$$
a_{j t}=r_{j t}-r_{j}
$$

Then, model (2)-(5) converts to the following model:

$$
\text { Minimize } \sum_{t=1}^{T}\left|\sum_{j=1}^{n} a_{j t} x_{j}\right| / T
$$

subject to

$$
\begin{aligned}
\sum_{j=1}^{n} r_{j} x_{j} \geq & \rho M_{0} \\
& \sum_{j=1}^{n} x_{j}=M_{0}
\end{aligned}
$$




$$
0 \leq x_{j} \leq u_{j,} j=1, \ldots, n
$$

Model (9)-(12) are equivalent to the following linear programming model:

$$
\operatorname{Minimize} \sum_{t=1}^{T} y_{t} / T
$$

subject to

$$
\begin{aligned}
& y_{t}+\sum_{j=1}^{n} a_{j t} x_{j} \geq 0, t=1, \ldots, T(14) \\
& y_{t}-\sum_{j=1}^{n} a_{j t} x_{j} \geq 0, t=1, \ldots, T
\end{aligned}
$$

$$
\sum_{j=1}^{n} r_{j} x_{j} \geq \rho M_{0}
$$

$$
\sum_{j=1}^{n} x_{j}=M_{0}
$$

$$
0 \leq x_{j} \leq u_{j,} j=1, \ldots, n
$$

Speranza [6] has further proposed the mean-semi absolute deviation model by using semi absolute deviation as risk measure instead of absolute deviation. This model is equivalent to the mean-absolute deviation model [1], but halves the number of required constraints. The mean-semi absolute deviation model [6] is formulated as follows:

$$
\text { Minimize } \sum_{t=1}^{T} y_{t} / T
$$

subject to

$$
\begin{array}{r}
y_{t}+\sum_{j=1}^{n} a_{j t} x_{j} \geq 0, t=1, \ldots, T \\
\sum_{j=1}^{n} r_{j} x_{j} \geq \rho M_{0} \\
\sum_{j=1}^{n} x_{j}=M_{0} \quad \text { (22) } 0 \leq x_{j} \leq u_{j, j}=1, \ldots, n
\end{array}
$$

The optimal portfolio is constructed using the mean-semi absolute deviation model (19)-(23) to minimize the portfolio risk and achieve the expected rate of return. The summary statistics of the optimal portfolio are also generated in this study. 


\section{RESULTS AND DISCUSSION}

Table 2 displays the mean and standard deviation of the weekly stocks returns of the 20 construction sector companies in this study.

Table 2. Mean and standard deviation of the 20 stocks returns

\begin{tabular}{|c|c|c|}
\hline Stock & Mean & Standard Deviation \\
\hline ASUPREM & 0.0010 & 0.0918 \\
\hline AZRB & 0.0009 & 0.0476 \\
\hline BENALEC & -0.0031 & 0.0457 \\
\hline BPURI & -0.0038 & 0.0372 \\
\hline CRESBLD & 0.0014 & 0.0439 \\
\hline EKOVEST & -0.0006 & 0.0480 \\
\hline FAJAR & -0.0019 & 0.0354 \\
\hline GADANG & 0.0054 & 0.0498 \\
\hline GAMUDA & 0.0012 & 0.0294 \\
\hline HSL & 0.0005 & 0.0329 \\
\hline IJM & -0.0013 & 0.0405 \\
\hline JAKS & 0.0029 & 0.0580 \\
\hline KEURO & 0.0005 & 0.0421 \\
\hline KIMLUN & 0.0008 & 0.0400 \\
\hline MITRA & 0.0041 & 0.0532 \\
\hline MUDAJYA & -0.0041 & 0.0493 \\
\hline MUHIBAH & 0.0034 & 0.0578 \\
\hline PRTASCO & 0.0027 & 0.0402 \\
\hline PUNCAK & -0.0006 & 0.0669 \\
\hline WCT & -0.0018 & 0.0411 \\
\hline
\end{tabular}

On the other hand, Table 3 displays the skewness and kurtosis of the weekly stocks returns of the 20 construction sector companies in this study. 
Table 3.Skewness and kurtosis of the 20 stocks returns

\begin{tabular}{|c|c|c|}
\hline Stock & Skewness & Kurtosis \\
\hline ASUPREM & 0.1361 & 2.9697 \\
\hline AZRB & 2.5456 & 14.0829 \\
\hline BENALEC & 0.2797 & 1.4396 \\
\hline BPURI & 0.3916 & 2.1582 \\
\hline CRESBLD & 3.2929 & 24.7405 \\
\hline EKOVEST & -3.7395 & 43.6247 \\
\hline FAJAR & 0.3483 & 1.8876 \\
\hline GADANG & 1.6259 & 5.3104 \\
\hline GAMUDA & 0.8359 & 5.7328 \\
\hline HSL & 1.2212 & 6.1952 \\
\hline IJM & -7.4293 & 92.6757 \\
\hline JAKS & 0.9512 & 3.1958 \\
\hline KEURO & 1.2848 & 6.8147 \\
\hline KIMLUN & 0.7264 & 5.9849 \\
\hline MITRA & -0.7646 & 7.3628 \\
\hline MUDAJYA & 0.0537 & 5.3372 \\
\hline MUHIBAH & 1.0180 & 5.4558 \\
\hline PRTASCO & 0.7073 & 1.9684 \\
\hline PUNCAK & 0.5093 & 13.7999 \\
\hline WCT & 0.0878 & 2.6896 \\
\hline
\end{tabular}

Table 2 and Table 3 show that the mean, standard deviation, skewness and kurtosis of the stock returns are different. Table 4 presents the optimal portfolio composition of the mean-semi absolute deviation model in percentage. 
Table 4. Optimal portfolio composition of the mean-semi absolute deviation model

\begin{tabular}{|c|c|}
\hline Stocks & Composition (Percentage) \\
\hline ASUPREM & 0.95 \\
\hline AZRB & 0.00 \\
\hline BENALEC & 0.00 \\
\hline BPURI & 0.00 \\
\hline CRESBLD & 7.48 \\
\hline EKOVEST & 1.19 \\
\hline FAJAR & 0.00 \\
\hline GADANG & 15.62 \\
\hline GAMUDA & 38.60 \\
\hline HSL & 8.38 \\
\hline IJM & 3.74 \\
\hline JAKS & 0.00 \\
\hline KEURO & 3.13 \\
\hline KIMLUN & 0.45 \\
\hline MITRA & 0.00 \\
\hline MUDAJYA & 0.00 \\
\hline MUHIBAH & 2.93 \\
\hline PRTASCO & 17.52 \\
\hline PUNCAK & 0.00 \\
\hline WCT & 0.00 \\
\hline
\end{tabular}

As shown in Table 4, the weight of each company that invested in the optimal portfolio is different. The optimal portfolio of the mean-semi absolute deviation model comprises ASUPREM (0.95\%), CRESBLD (7.48\%), EKOVEST (1.19\%), GADANG (15.62\%), GAMUDA (38.60\%), HSL (8.38\%), IJM (3.74\%), KEURO (3.13\%), KIMLUN (0.45\%), MUHIBAH (2.93\%) and PRTASCO (17.52\%). AZRB, BENALEC, BPURI, FAJAR, JAKS, MITRA, MUDAJYA, PUNCAK and WCT are not selected to be invested because these construction sector companies give the composition value $0.00 \%$ in the optimal portfolio. GAMUDA (38.60\%) is the largest component stock in the optimal portfolio. 
Table 5 displays the summary statistics of the mean-semi absolute deviation optimal portfolio.

Table 5. Summary statistics of the mean-semi absolute deviation optimal portfolio

\begin{tabular}{cc}
\hline Summary Statistics & Optimal Portfolio Value \\
\hline Portfolio Mean Return & 0.0020 \\
Portfolio Risk & 0.0080 \\
Portfolio Skewness & 0.9692 \\
Portfolio Kurtosis & 7.1922
\end{tabular}

As reported in Table 5, the mean-semi absolute deviation optimal portfolio gives the mean return at the rate of 0.0020 with the risk of 0.0080 . It implies that the investors can achieve the expected rate of return with the minimum risk by using the mean-semi absolute deviation model. Furthermore, the optimal portfolio gives the skewness and kurtosis value at 0.9692 and 7.1922 respectively.

\section{CONCLUSION}

In this paper, the mathematical formulation of the mean-semi absolute deviation model is discussed. The optimal portfolio is constructed by using the mean-semi absolute deviation model. The results of this study show that the constructed optimal portfolio can minimize the portfolio risk and can achieve the investors target rate of return. Furthermore, the composition of each stock invested in the optimal portfolio is different. This study is significant because it will give impact to the investors in portfolio management by minimizing the portfolio risk and can achieve the expected rate of return. The future research of this study should be extended to other sectors besides construction sector companies in Malaysia.

\section{ACKNOWLEDGEMENTS}

This study is supported by UniversitiKebangsaan Malaysia (UKM) research fund.

\section{REFERENCES}

[1] Konno H, Yamazaki H. Mean-absolute deviation portfolio optimization model and its applications to Tokyo stock market. Management Science, 1991, 37(5):519-531

[2] Ali A K. Risk and investment opportunities in portfolio optimization. European Journal of 
Finance and Banking Research, 2007, 1(1):1-15

[3] Bugra B, Fatih K. Linear programming on portfolio optimization: Empirical evidence from bist mining industry index. Global Journal of Management and Business Research, 2016, $16(2): 31-36$

[4] Konno H. Portfolio optimization of small scale fund using mean-absolute deviation model.International Journal of Theoretical and Applied Finance, 2003, 6(4):403-418

[5] Zenios S A, Kang P. Mean-absolute deviation portfolio optimization for mortgage-backed securities. Annals of Operations Research, 1993, 45:433-450

[6] Speranza M G. Linear programming models for portfolio optimization. Finance, 1993, $14: 107-123$

[7] Chiodi L, Mansini R, Speranza M G. Semi-absolute deviation rule for mutual funds portfolio selection.Annals of Operations Research, 2003, 124:245-265

[8] Speranza M G. A heuristic algorithm for a portfolio optimization model applied to the Milan stock market. Computers andOperations Research, 1996, 23(5):433-441

[9] Liu Y, Qin Z. Mean semi-absolute deviation model for uncertain portfolio optimization problem. Journal of Uncertain Systems, 2012, 6(4):299-307

[10] Amir A, Alireza A, Sadegh S. Development of data envelopment analysis for the performance evaluation of green supply chain with undesirable outputs. International Journal of Supply and Operations Management, 2016, 3(2):1267-1283

[11] Siek D, Xu S, Yu W, Abdul A G, Chamroeun D. Optimization model of small-scale chicken production in Cambodia. Open Journal of Social Sciences, 2016, 4:295-299

[12] Ramos R P, Isler P R, Florentino H D O, Jones D, Nervis J J. An optimization model for the combined planning and harvesting of sugarcane with maturity considerations. African Journal of Agricultural Research, 2016, 11(40):3950-3958

[13] Vivi S, Said M, Raja M, Muhammad N. Optimization of smallholder palm oil in Nagan Raya and Aceh TamiangAceh province. International Journal of Contemporary Applied Sciences, 2016, 3(4):1-17

\section{How to cite this article:}

Lam, W. H., Saiful, H. J.and Lam, W. S.Portfolio optimization of the construction sector companies in Malaysia with mean-semi absolute deviation model. J. Fundam. Appl. Sci., 2017, 9(5S), 13-22. 